\title{
Magnitude and associated factors of unintended pregnancy in Ethiopia: a multilevel analysis using 2016 EDHS data
}

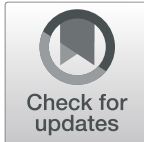

\author{
Achamyeleh Birhanu Teshale ${ }^{*}$ and Getayeneh Antehunegn Tesema
}

\begin{abstract}
Background: Unintended pregnancy has become a significant public health and reproductive health problem that has had a substantial and appreciable adverse impact on mother, child, and the general public. Despite the paramount negative effects of unintended pregnancy, many pregnancies are unintended in Ethiopia. Therefore, this study aimed to determine the prevalence and associated factors of unintended pregnancy in Ethiopia.

Methods: This study was based on the nationally representative 2016 Ethiopian Demographic and Health Survey data. We used a total weighted sample of 7590 reproductive-aged women who gave birth in the 5 years preceding the survey. A multi-level logistic regression analysis was used to account for the hierarchal nature of the DHS data. In the multivariable multilevel analysis, those variables with $p$-value $<0.05$ were considered to be significantly associated with unintended pregnancy.

Result: The prevalence of unintended pregnancy was $26.6 \%$ [95\%Cl: 25.6, 27.6]. In the multivariable multilevel logistic regression analysis; individual level variables such as being in the age group 20 to 34 [adjusted odds ratio $(A O R)=0.57 ; 95 \% C l: 0.41,0.79]$ and 35 to $49[\mathrm{AOR}=0.68 ; 95 \% \mathrm{Cl}: 0.47,0.97]$, being follower of Muslim religion $[\mathrm{AOR}=0.73 ; 95 \% \mathrm{Cl}: 0.60,0.88]$, being married $[\mathrm{AOR}=0.46 ; 95 \% \mathrm{Cl}: 0.37-0.58]$, household size of four to six $[\mathrm{AOR}=$ $1.38 ; 95 \% \mathrm{Cl}: 1.10,1.69]$ and seven and above $[\mathrm{AOR}=1.54 ; 95 \% \mathrm{Cl}: 1.20,1.99]$, and being multiparous $[\mathrm{AOR}=1.36$; $95 \% \mathrm{Cl}: 1.10,1.69]$ and grand multiparous $[A O R=1.92 ; 95 \% \mathrm{Cl}: 1.47,2.52]$ were significantly associated with unintended pregnancy. Among community level variables; being living in large central [AOR $=2.56 ; 95 \% \mathrm{Cl}$ : 2.06, 3.17] and metropolitan regions $[A O R=1.91 ; 95 \% \mathrm{Cl}: 1.44,2.53]$ were significantly associated with unintended pregnancy.
\end{abstract}

Conclusion: In this study the prevalence of unintended pregnancy was high. Maternal age, religion, marital status, household size, parity, and region were the most important factors associated with unintended pregnancy. Special attention should, therefore, be given to younger, single, multiparous and grand multiparous women, and not follower of Muslim religion as well as mothers from large central and metropolitan regions in terms of increasing accessibility and affordability of maternal health services, which could minimize unintended pregnancy.

Keywords: Magnitude, Unintended pregnancy, Multilevel analysis, Ethiopia

\footnotetext{
*Correspondence: achambir08@gmail.com

Department of Epidemiology and Biostatistics, Institute of Public Health, College of Medicine and Health Sciences, University of Gondar, Gondar, Ethiopia
}

(c) The Author(s). 2020 Open Access This article is licensed under a Creative Commons Attribution 4.0 International License, which permits use, sharing, adaptation, distribution and reproduction in any medium or format, as long as you give appropriate credit to the original author(s) and the source, provide a link to the Creative Commons licence, and indicate if changes were made. The images or other third party material in this article are included in the article's Creative Commons licence, unless indicated otherwise in a credit line to the material. If material is not included in the article's Creative Commons licence and your intended use is not permitted by statutory regulation or exceeds the permitted use, you will need to obtain permission directly from the copyright holder. To view a copy of this licence, visit http://creativecommons.org/licenses/by/4.0/. The Creative Commons Public Domain Dedication waiver (http://creativecommons.org/publicdomain/zero/1.0/) applies to the data made available in this article, unless otherwise stated in a credit line to the data. 


\section{Background}

Unintended pregnancy is a pregnancy that is either unwanted (occurred when no children or no more children were desired) or mistimed (occurred earlier than desired) for at least one of the couples $[1,2]$. Unintended pregnancy has been a major or troubling public health and reproductive health issue imposing a great and appreciable adverse consequence to the mother, child, and the public in general [3]. Mothers with unintended pregnancy are at risk of many devastating complications such as induced abortion to the extent of causing maternal death, higher crime rates, maternal depression, and parenting as well as family stress, reduced workforce efficiency, and reduced academic achievement [3-7]. In addition, mothers with unintended pregnancies are more likely to be careless on this pregnancy and might have late ante-natal care initiation and decreased delivery service utilization [8].

Abortion is a serious and devastating complication of unintended pregnancy in which one third (30.4\%) of unintended pregnancies end up with abortion [6]. Another study showed that the occurrence of abortion is the primary consequence of unintended pregnancy in which about half of all unintended pregnancies end with abortion and this abortion comes with many complications directly related to the procedure such as hemorrhage, uterine perforation, cervical injury, and infection [8].

Overall, evidences revealed that unintended pregnancy is one of the most critical challenge facing the public health system and impose significant financial and social costs on society. In the world, between 2010 and 2014, an estimated 44\% (62 unintended pregnancies per 1000 women) of pregnancies were unintended with a great discrepancy between developing (65 unintended pregnancies per 1000 women) and developed countries (45 per 1000 women) [9]. In sub-Saharan Africa, the overall prevalence of unintended pregnancy is $29 \%$ which ranges from $10.8 \%$ in Nigeria to $54.5 \%$ in Namibia [10]. Different studies conducted in Ethiopia also revealed that the prevalence of unintended pregnancy ranges from 13.7 to $41.5 \%$ [11-17].

Evidences have shown that socio-demographic factors such as; maternal age [15, 16, 18-22], level of education of the mother [19, 21-23], religion [17, 24, 25], marital status $[12,13,16,18,26,27]$, distance from the nearest health facility [13], parity [14, 16, 17, 21, 22], household size [12, 28, 29], income/wealth status $[10,19,25]$, knowledge of ovulation cycle [14], knowledge of family planning [21], ever had of terminated pregnancy $[15,16,20]$, residence $[17,21,25]$ and region $[22,29]$ are the main factors associated with unintended pregnancy.

Tackling unintended pregnancy has a huge benefit in saving the costs of abortion and its complications, as well as reducing the morbidity and mortality of mothers and children [30]. Given the paramount negative consequences of unintended pregnancy for both the mother and the fetus, up to our knowledge, there was a limited study on unintended pregnancy that is based on nationally representative data in Ethiopia. Therefore, this study aimed to determine the prevalence and associated factors of unintended pregnancy. The finding from this study will give an insight for health care professionals and policymakers in understanding the burden of unintended pregnancy and its associated factors for setting possible interventions and ensure or deliver safe and reliable service to the reproductive age group women.

\section{Method}

\section{Data source and population}

This study was based on the nationally representative 2016 Ethiopian Demographic and Health Survey (EDHS) which was conducted from January 18, 2016, to June 27, 2016.

The survey used the Ethiopia Population and Housing Census (PHC) conducted in 2007 as a sampling frame. The frame is a complete list of 84,915 enumeration areas (EAs) created for the 2007 PHC. The sample used for the survey was stratified and selected using two stages. In the first stage, a total of 645 EAs (202 in urban areas and 443 in rural areas) were selected with probability proportional to EA size. In the second stage, 28 households per cluster were selected with an equal probability systematic selection. Detailed information was collected on issues related to the reproductive health (fertility and fertility preference, marriage, awareness and the use of family planning methods), adult and childhood morbidity and mortality as well as awareness and attitudes towards HIV/AIDS and other important public health issues from 16,650 households, 15,683 female respondents, and 12,688 male respondents. Further information regarding the sampling technique and questionnaire, in general about the survey, can be obtained from the EDHS 2016 report [31].

Our analysis was based on women's data (IR data) set of EDHS 2016 which was accessed from the Measure demographic and health survey (DHS) program website (http://www.measuredhs.com). A total weighted sample of 7590 reproductive age women (15-49 years) who gave birth in the 5 years preceding the survey was used.

\section{Study variables}

The dependent variable was unintended pregnancy which includes pregnancies that are wanted no more or wanted later. For this study, the independent variables were classified as individual level and community level variables. The individual-level variables were maternal age, maternal educational status, maternal occupation, marital status, religion, parity, household size, wealth status, media exposure, ever had of terminated pregnancy and knowledge of ovulation cycle. The community-level variables in this study were the perception of distance from the health facility, residence, and region. Some of the variables were 
re-coded to make suitable for the study such as wealth status, re-coded as poor $=0$, middle $=1$, rich $=2$ whereby women in the poorest and poorer category were referred to as the "poor"; those who were above the poorer wealth category but not up to those in the high category were categorized as middle whilst those in the high wealth category (rich and richest) were recoded as rich. The other variable recoded was region in which; Afar, Somali, Benishangul, and Gambela as "small peripheral regions", Tigray, Amhara, Oromia, and Sothern Nations Nationalities and Peoples Region (SNNPR) as "large central regions" and Harari, Dire Dawa, and Addis Ababa as "metropolitans", based on their geopolitical features consistent with a previous study from Ethiopia [32]. Other important independent variables were also recoded or recategorized to make suitable for analysis.

\section{Data management and analysis}

The extraction of data, coding, and analysis was done using Stata 14 software. The data were weighted with the available sample weight factor (v005) within the EDHS dataset to minimize the effect of sampling bias. A multi-level logistic regression analysis was used to account for the hierarchal nature of the DHS data and bivariable multilevel logistic regression analysis was performed to estimate the crude odds ratios at $95 \%$ confidence interval and those variables with $p$-value $<0.20$ were considered for multivariable analysis. In the multivariable multilevel logistic analysis, those variables with $p$-value $<0.05$ were considered to be significantly associated with unintended pregnancy.

After selecting variables for multivariable analysis, four models containing variables of interest were fitted. These models were model 1 without explanatory variables, model 2 which examined the effects of individual-level characteristics, model 3 examined the effect of community-level variables and model 4 which examined the effects of both individual and community level characteristics simultaneously. The random effect results were estimated using three different methods, the Intra-Class Correlation (ICC), median odds ratio (MOR), and proportional change in variance (PCV). Since these models were nested deviance was used to assess the model fitness.

\section{Results}

\section{Background characteristics of respondents}

Table 1 summarizes the background characteristics of the study participants. More than two-thirds of study participants were between 20 and 34 years of age with an overall mean age of $29.3( \pm 6.8)$ years. The majority (63.1\%) of respondents had no formal education and $43.5 \%$ of women had poor wealth status. Most, $93.7 \%$ of women were married while two-third of them had no media exposure. Regarding household size, half of the
Table 1 Background characteristics of respondents

\begin{tabular}{|c|c|c|}
\hline Variables & Frequency & Percentage \\
\hline \multicolumn{3}{|l|}{ Maternal age } \\
\hline $15-19$ & 339 & 4.47 \\
\hline $20-34$ & 5292 & 69.72 \\
\hline $35-49$ & 1959 & 25.82 \\
\hline \multicolumn{3}{|l|}{ Maternal education } \\
\hline No formal education & 4791 & 63.12 \\
\hline Primary & 2150 & 28.32 \\
\hline Secondary and above & 649 & 8.55 \\
\hline \multicolumn{3}{|l|}{ Religion } \\
\hline Orthodox & 2882 & 37.97 \\
\hline Muslim & 1652 & 21.76 \\
\hline Protestant & 2824 & 37.21 \\
\hline Other & 232 & 3.06 \\
\hline \multicolumn{3}{|l|}{ Marital status } \\
\hline Married & 7109 & 93.66 \\
\hline Not married & 481 & 6.34 \\
\hline \multicolumn{3}{|l|}{ Occupation } \\
\hline Working & 4078 & 53.73 \\
\hline Not working & 3512 & 46.27 \\
\hline \multicolumn{3}{|l|}{ Wealth index } \\
\hline Poor & 3306 & 43.55 \\
\hline Middle & 1588 & 20.93 \\
\hline Rich & 2696 & 35.52 \\
\hline \multicolumn{3}{|l|}{ Media exposure } \\
\hline Yes & 2621 & 34.53 \\
\hline No & 4969 & 65.47 \\
\hline \multicolumn{3}{|l|}{ Household size } \\
\hline 1 to 3 & 1033 & 13.61 \\
\hline 4 to 6 & 3889 & 51.23 \\
\hline 7 and above & 2668 & 35.26 \\
\hline \multicolumn{3}{|l|}{ Parity } \\
\hline Primiparous & 1434 & 18.90 \\
\hline Multiparous & 3190 & 41.02 \\
\hline Grand multiparous & 2966 & 39.08 \\
\hline \multicolumn{3}{|c|}{ Ever had of terminating a pregnancy } \\
\hline Yes & 6910 & 91.04 \\
\hline No & 680 & 8.96 \\
\hline \multicolumn{3}{|c|}{ Distance from the health facility } \\
\hline Big problem & 4407 & 58.06 \\
\hline Not a big problem & 3183 & 41.94 \\
\hline \multicolumn{3}{|l|}{ Residence } \\
\hline Urban & 969 & 12.77 \\
\hline Rural & 6621 & 87.23 \\
\hline \multicolumn{3}{|l|}{ Region } \\
\hline Large central & 6900 & 90.90 \\
\hline Small peripheral & 441 & 5.81 \\
\hline Metropolitan & 249 & 3.28 \\
\hline
\end{tabular}


respondents were from a household size of four to six. The majority of the women were from rural areas and large peripheral regions.

\section{Prevalence of unintended pregnancy}

In this study $73.4 \%$ [95\%CI: 72.4, 74.4] of pregnancies were intended and $26.6 \%$ [95\%CI: 25.6, 27.6] pregnancies were unintended (Fig. 1).

\section{Factors associated with unintended pregnancy}

Table 2 showed the random effect model. In the null model, about $17 \%$ of the total variation on unintended pregnancy was occurred at the community level and is attributable to the community-level factors. The highest MOR value (2.17) in the null model revealed there was a variation of unintended pregnancy between clusters. Furthermore, the highest (36.4\%) PCV in the final model (Model 4) indicates that $36.4 \%$ of the variation in unintended pregnancy across communities was explained by both individual and community level factors. The model fitness was checked using deviance and the model with the lowest deviance (Model 4) was the best-fitted model.

Table 3 showed the fixed effects model. In the bivariable multilevel modeling, all of the independent (both individual level and community level variables), except knowledge of the ovulation cycle, had shown statistically significant association at a $p$-value of $<0.20$. In the multivariable multilevel logistic regression analysis, the odds of unintended pregnancy was $43 \%$ [adjusted odds ratio $(\mathrm{AOR})=0.57 ; 95 \% \mathrm{CI}: 0.41,0.79]$ and $32 \% \quad[\mathrm{AOR}=0.68$; $95 \%$ CI: $0.47,0.97$ ] lower among mothers whose age was between 20 to 34 and 35 to 49 respectively as compared to those mothers whose age was 15 to 19 years. Mothers whose religion were Muslim had 27\% [AOR $=0.73$; $95 \%$ CI: $0.60,0.88$ ] lower odds of unintended pregnancy as compared to those mothers whose religion was Orthodox Christian. Regarding marital status, married

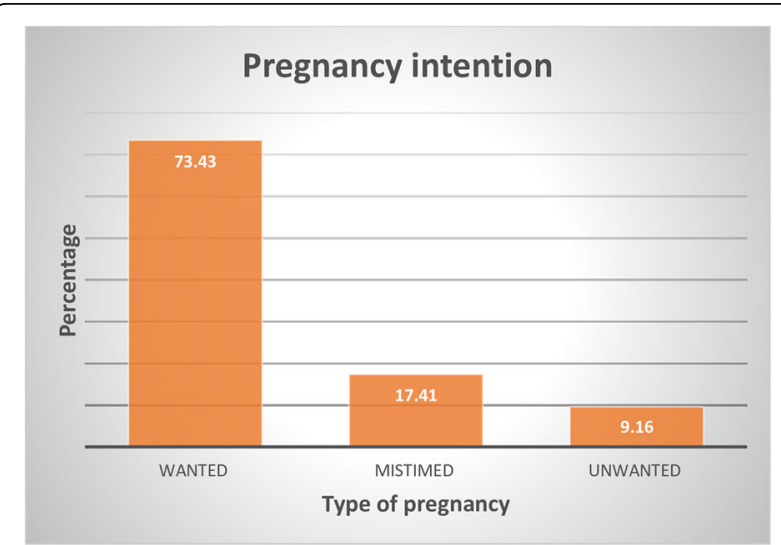

Fig. 1 Prevalence of intended or wanted, unwanted and wanted but mistimed pregnancy in Ethiopia
Table 2 Random effect (community-level clustering) in unintended pregnancy and model fitness

\begin{tabular}{lllll}
\hline Parameter & Model 1 & Model 2 & Model 3 & Model 4 \\
\hline MOR & 2.17 & 2.00 & 1.87 & 1.85 \\
PCV & Reff. & 0.204 & 0.345 & 0.364 \\
ICC & 0.17 & 0.14 & 0.12 & 0.11 \\
Deviance & 7034.30 & 6815.46 & 6916.26 & 6740.00 \\
\hline
\end{tabular}

mothers had 54\% $[\mathrm{AOR}=0.46$; 95\%CI: $0.37-0.58]$ lower odds of unintended pregnancy as compared to their counterparts. Respondents with a household size of four to six and seven and above had $1.38[\mathrm{AOR}=1.38 ; 95 \% \mathrm{CI}$ : $1.10,1.69]$ and 1.54 [AOR $=1.54 ; 95 \% \mathrm{CI}: 1.20,1.99]$ times higher odds of unintended pregnancy respectively as compared with a household size of one to three. Multiparous and grand multiparous women had $1.36[\mathrm{AOR}=1.36$; 95\%CI: $1.10,1.69]$ and $1.92[\mathrm{AOR}=1.92 ; 95 \% \mathrm{CI}: 1.47$, $2.52]$ times higher odds of unintended pregnancy respectively as compared to primiparous women. A woman who was living in large central regions and metropolitan regions had $2.56[\mathrm{AOR}=2.56$; 95\%CI: 2.06, 3.17] and 1.91 [AOR $=1.91 ; 95 \% \mathrm{CI}: 1.44,2.53]$ times higher odds of unintended pregnancy respectively as compared to a woman from small peripheral regions.

\section{Discussion}

The study aimed to assess the prevalence and associated factors of unintended pregnancy in Ethiopia using EDHS 2016 data. According to the findings of this study, the estimated prevalence of unintended pregnancy in Ethiopia was $26.6 \%$ which is consistent with different studies done in Ethiopia [13, 17, 33]. This prevalence of unintended pregnancy in our study is less than studies done in Addis Ababa [27], Arsi Negele [16], Jimma [11], Botswana [34], and Ghana [22]. But our finding is higher than studies conducted in Tepi General Hospital Ethiopia [35], Belessa Woreda Ethiopia [15], a study based on 2011 EDHS data [14], Britain [23] and Cambodia [20]. This discrepancy might be due to the difference in the study population in which in the above studies (except studies in Ghana, 2011 EDHS data and Britain) pregnant women on antenatal care were their study subjects. Besides, most of the above studies were based on small sample size or they are mostly facility-based cross-sectional studies. The other possible explanation is due to the study period and different in socio-cultural characteristics as well as the difference in the availability and accessibility of maternal health services including family planning methods. Moreover, the discrepancy of our findings to that of a study in Britain might be due to Britain is one of a developed country in the world with accessible and organized maternal health services including family planning to prevent unintended pregnancy. 
Table 3 Multilevel logistic regression analysis of individual and community-level factors associated with unintended pregnancy in Ethiopia

\begin{tabular}{|c|c|c|c|c|}
\hline Respondent characteristics & Model 1 & Model 2 (AOR 95\%Cl) & Model 3 (AOR 95\%Cl) & Model 4 (AOR 95\%Cl) \\
\hline \multicolumn{5}{|c|}{ Individual-level and household level factors } \\
\hline \multicolumn{5}{|l|}{ Maternal age (years) } \\
\hline $15-19$ & & 1.00 & & 1.00 \\
\hline $20-34$ & & $0.59[0.43-0.82]$ & & $0.57[0.41-0.79]$ \\
\hline $35-49$ & & $0.71[0.50-1.03]$ & & $0.68[0.47-0.97]$ \\
\hline \multicolumn{5}{|l|}{ Maternal education } \\
\hline No formal education & & $0.88[0.68-1.13]$ & & $0.84[0.65-1.09]$ \\
\hline Primary & & $1.15[0.92-1.44]$ & & $1.19[0.87-0.97]$ \\
\hline Secondary and above & & 1.00 & & 1.00 \\
\hline \multicolumn{5}{|l|}{ Religion } \\
\hline Orthodox & & 1.00 & & 1.00 \\
\hline Protestant & & $0.98[0.79-1.12]$ & & $1.17[0.95-1.45]$ \\
\hline Muslim & & $0.54[0.45-0.65]$ & & $0.73[0.60-0.88]$ \\
\hline Others & & $0.82[0.51-1.32]$ & & $0.98[0.61-1.57]$ \\
\hline \multicolumn{5}{|l|}{ Marital status } \\
\hline Not married & & 1.00 & & 1.00 \\
\hline Married & & $0.46[0.37-0.57]$ & & $0.46[0.37-0.58]$ \\
\hline \multicolumn{5}{|l|}{ Occupation } \\
\hline Working & & $1.13[0.98-1.29]$ & & $1.12[0.98-1.28]$ \\
\hline Not working & & 1.00 & & 1.00 \\
\hline \multicolumn{5}{|l|}{ Household wealth } \\
\hline Poor & & 1.00 & & 1.00 \\
\hline Middle & & $1.15[0.95-1.40]$ & & $1.01[0.83-1.23]$ \\
\hline Rich & & $1.21[0.10-1.45]$ & & $1.03[0.85-1.26]$ \\
\hline \multicolumn{5}{|l|}{ Media exposure } \\
\hline No & & 1.00 & & 1.00 \\
\hline Yes & & $1.06[0.90-1.24]$ & & $1.01[0.86-1.19]$ \\
\hline \multicolumn{5}{|l|}{ Household size } \\
\hline 1 to 3 & & 1.00 & & 1.00 \\
\hline 4 to 6 & & $1.41[1.13-1.77]$ & & $1.38[1.10-1.72]$ \\
\hline 7 and above & & $1.57[1.22-2.02]$ & & 1.54 [1.20-1.99] \\
\hline \multicolumn{5}{|l|}{ Parity } \\
\hline Primiparous & & 1.00 & & 1.00 \\
\hline Multiparous & & $1.33[1.07-1.66]$ & & $1.36[1.10-1.69]$ \\
\hline Grand multiparous & & $1.87[1.43-2.44]$ & & $1.92[1.47-2.52]$ \\
\hline \multicolumn{5}{|c|}{ Ever had of a terminated pregnancy } \\
\hline Yes & & $1.22[0.99-1.51]$ & & $1.19[0.97-1.48]$ \\
\hline No & & 1.00 & & 1.00 \\
\hline \multicolumn{5}{|l|}{ Community-level factors } \\
\hline \multicolumn{5}{|l|}{ Residence } \\
\hline Urban & & & 1.00 & 1.00 \\
\hline Rural & & & $0.80[0.64-1.01]$ & $0.82[0.62-1.07]$ \\
\hline Region & & & & \\
\hline
\end{tabular}


Table 3 Multilevel logistic regression analysis of individual and community-level factors associated with unintended pregnancy in Ethiopia (Continued)

\begin{tabular}{|c|c|c|c|c|}
\hline Respondent characteristics & Model 1 & Model 2 (AOR 95\%Cl) & Model 3 (AOR 95\%Cl) & Model 4 (AOR 95\%Cl) \\
\hline Metropolitan & & & $1.81[1.38-2.38]$ & $2.56[2.06-3.17]$ \\
\hline Large central & & & $2.92[2.41-3.52]$ & $1.91[1.44-2.53]$ \\
\hline Small peripheral & & & 1.00 & 1.00 \\
\hline \multicolumn{5}{|c|}{ Distance from the health facility } \\
\hline Big problem & & & 1.00 & 1.00 \\
\hline Not a big problem & & & $1.08[0.93-1.24]$ & $1.07[0.93-1.24]$ \\
\hline
\end{tabular}

Note: AOR Adjusted Odds Ratio, Cl Confidence Interval, Other Catholic, Traditional, Other

In multivariable multilevel logistic regression analysis maternal age, religion, marital status, household size, parity, and region were significantly associated with unintended pregnancy in Ethiopia. Consistent with different studies conducted in Pakistan [21], Nigeria [19], South Africa [36], Malawi [37], Kenya [18] and Cambodia [20], older mothers had lower odds of unintended pregnancy. This might be because of older women had higher knowledge on contraceptive methods to prevent unintended pregnancy and lower contraceptive failure rate [21,38]. Additionally, this group of women might be more literate about the importance and accessibility of reproductive or maternal health services. Another plausible explanation is that older women are less likely to engage in risky sexual behaviors such as unprotected sexual intercourse and sex under the influence of drinking alcohol $[39,40]$.

In this study religion is another most important variable which significantly associated with unintended pregnancy. That is Muslim mothers were less likely to report having an unintended pregnancy as compared to orthodox Christian mothers. This finding is similar to studies done in Ghana [25], Addis Zemen [17] and Wolayitasodo [24]. Such correlation could be because contraceptive usage is strongly not encouraged in Muslim culture, and this in fact avoids unintended pregnancy due to contraceptive failure. Moreover, most Muslim mothers count each child as God's gift, and these mean that Muslim mothers don't bother about unintended pregnancy. Furthermore, relative to orthodox Christians, Muslim mothers tended to have higher fertility and greater decision-making power over their wellbeing.

Similar to other studies done in Ethiopia [12, 13, 16, 26], and Kenya [18] the current study at hand revealed that unmarried mothers were at higher odds of unintended pregnancy. The potential reason is that unmarried women may unintentionally participate in sexual activity and this is most likely unwanted if the pregnancy is occurred. Additionally, our culture and community might cause a significant influence on unmarried women not to use contraceptive because of sex is not recommended before the mother is married.

Consistent with other studies conducted in Ethiopia $[12,29]$ and Nigeria [28] unintended pregnancy is significantly associated with household size, in which mothers from the household size of four and above had higher odds of unintended pregnancy. This might be due to mothers with higher household size might be busy in caring their family and this affects their getting of information and accessing and utilization of maternal health services such as contraceptive methods which in turn end up with unintended pregnancy.

Moreover in this study multiparous and grand multiparous mothers had higher odds of unintended pregnancy and this is congruent with other studies conducted in Ethiopia [14, 16, 17], Ghana [22] and Pakistan [21]. The possible explanation might be these women have enough or adequate number of children with a decreasing intention for the next pregnancy or childbirth.

Furthermore, region was an important communitylevel variable and mothers from metropolitan and large peripheral regions had higher odds of unintended pregnancy. This regional variation indicated in this study is in line with studies conducted in Ethiopia [29], Kenya [18] and Ghana [22]. This is since pregnancies may be appreciated and accepted in small peripheral regions and mothers in this region did not think about unintended pregnancy. But women in metropolitan and large central regions might be busy because of their intention to advance their economic status and mostly their pregnancies are more likely to be unintended.

This study had strength since it was based on nationally representative data with large sample size. The other strength was we used an appropriate statistical approach (multilevel analysis) to accommodate the hierarchical nature of the data. Moreover, since it is based on the national survey data the study has the potential to give insight for policy-makers and program planners to design appropriate intervention strategies both at national and regional levels. However, this study had limitations in that the EDHS survey is mostly based on respondents' self-report and might have the possibility of recall bias. Again, this study only shows the associations between unintended pregnancy and some important individuallevel and community-level factors that is it did not establish causality. 


\section{Conclusion}

In this study the prevalence of unintended pregnancy was high. In a multivariable multilevel analysis, both individual and community level variables were significantly associated with unintended pregnancy in Ethiopia. Of individual-level variables younger age group, being not follower of Muslim religion, unmarried, mothers with higher household size, and multiparous and grand multiparous mothers were at higher odds of unintended pregnancy. Among community-level variables; mothers living in large central regions and metropolitan were at higher odds of unintended pregnancy. Therefore, special attention could be taken for these high-risk groups in terms of increasing accessibility and availability of maternal health services and by doing so this devastating health problem (unintended pregnancy) could be decreased.

\section{Abbreviations}

AOR: Adjusted Odds Ratio; Cl: Confidence Interval; DHS: Demographic and Health Survey; EAs: Enumeration Areas; EDHS: Ethiopian Demographic and Health Survey; ICC: Intra Class Correlation; MOR: Median Odd Ratio;

PCV: Proportional Change in Variance; PHC: Population and Housing census

\section{Acknowledgments}

We would like to acknowledge the MEASURE DHS program for permitting us to obtain and use the 2016 EDHS data set.

\section{Authors' contributions}

$A B T$, initiated the research concept, wrote up of the research proposal, analyzed the data, presented the results and wrote up the draft manuscript GAT involved in data analysis, interpreted results and discussions, reviewed and finalized the manuscript document. Both authors read and approved the final manuscript.

\section{Funding}

No, any funding was received from any organization.

\section{Availability of data and materials}

All result-based data are available within the manuscript and anyone can access the data set online from www.measuredhs.com.

\section{Ethics approval and consent to participate}

For this study ethical approval was not required since this is a secondary analysis of the 2016 EDHS data. But we registered and requested access to EDHS datasets from DHS on-line archive and received approval to access and download the data files.

\section{Consent for publication}

Not applicable.

\section{Competing interests}

The authors declare that they have no competing interests.

Received: 6 February 2020 Accepted: 20 May 2020

Published online: 29 May 2020

\section{References}

1. CDC. Unintended Pregnancy. 2019.

2. Santelli BJ, Rochat R, Hatfield K, Gilbert C, Curtis K, Cabral R, et al. The Measurement and Meaning of Unintended Pregnancy; 1999. p. 94-101.

3. Yazdkhasti M, Pourreza A, Pirak A. Unintended Pregnancy and Its Adverse Social and Economic Consequences on Health System : A Narrative Review Article. Iran J Public Health. 2015:44(1):12-21..

4. Bahk J, Yun S, Kim Y, Khang Y. Impact of unintended pregnancy on maternal mental health : a causal analysis using follow up data of the Panel Study on Korean Children ( PSKC ); 2015. p. 1-12.
5. Thomas A, Monea E. Children and Families at BROOKINGS The High Cost of Unintended Pregnancy. 2011;(July).

6. Swannell C. Almost one-third of unplanned pregnancies end in abortion. Med J Aust. 1.

7. Gipson JD, Koenig MA, Hindin MJ, Gipson JD, Koenig MA, Hindin MJ. The effects of unintended pregnancy on infant, Child, and Parental Health : A Review of the Literature. Stud Fam Plan. 2019;39(1):18-38.

8. Brown SS, Eisenberg L. The Best Intentions: Unintended Pregnancy and the Well-Being of Children and Families; 1995.

9. Bearak J, Popinchalk A, Alkema L, Sedgh G. Articles Global, regional , and subregional trends in unintended pregnancy and its outcomes from 1990 to 2014 : estimates from a Bayesian hierarchical model. Lancet Glob Health. 2014; 6(4):e380-9. Available from:. https://doi.org/10.1016/S2214-109X(18)30029-9.

10. Kwabena E, Id A, Budu E, Sambah F, Baatiema L, Appiah F, et al. Prevalence and determinants of unintended pregnancy in sub-Saharan Africa : A multicountry analysis of demographic and health surveys; 2019. p. 1-16.

11. Beyene GA. Prevalence of unintended pregnancy and associated factors among pregnant mothers in Jimma town, southwest Ethiopia : a cross sectional study. Contracept Reprod Med. 2019;4:1-8.

12. Yenealem F, Niberet $G$. Prevalence and associated factors of unintended pregnancy among pregnant woman in Gondar town , North west Ethiopia. BMC Res Notes. 2019:1-5. Available from. https://doi.org/10.1186/s13104-019-4203-6.

13. Melese KG, Gebrie MH, Badi MB, Mersha WF. Unintended Pregnancy in Ethiopia : Community Based Cross-Sectional Study. Obstet Gynecol Int. 2016;2016:4374791.

14. Habte D, Teklu S, Melese T, Magafu MGMD. Correlates of Unintended Pregnancy in Ethiopia : Results From a National Survey Correlates of Unintended Pregnancy in Ethiopia : Results From a National Survey. 2014;(December 2013).

15. Tsegaye AT, Mengistu M, Shimeka A. Prevalence of unintended pregnancy and associated factors among married women in west Belessa Woreda. Northwest. 2018:1-8.

16. Fite RO, Mohammedamin A, Abebe TW. Unintended pregnancy and associated factors among pregnant women in Arsi Negele Woreda, West Arsi Zone, Ethiopia. BMC Res Notes. 2018;11(1):671.

17. Ayalew $Y, I d$ G, Yitayew AE. Prevalence and determinant factors of unintended pregnancy among pregnant women attending antenatal clinics of Addis Zemen hospital; 2019. p. 1-12.

18. Ikamari L, Izugbara C, Ochako R. Prevalence and determinants of unintended pregnancy among women in Nairobi, Kenya. BMC pregnancy and childbirth. 2013;13:1-9.

19. Yaya S, Amouzou A, Uthman OA, Ekholuenetale M, Bishwajit G, Udenigwe $O$, et al. Prevalence and determinants of terminated and unintended pregnancies among married women : analysis of pooled cross-sectional surveys in Nigeria. 2018;

20. Rizvi F, Williams J, Hoban E. Factors influencing unintended pregnancies amongst adolescent girls and young women in Cambodia; 2019.

21. Habib A, Greenow CR-. Prevalence and determinants of unintended pregnancies amongst women attending antenatal clinics in Pakistan 2017; 17(January):1-10.

22. Nyarko SH. Unintended Pregnancy among Pregnant Women in Ghana: Prevalence and Predictors. J Pregnancy. 2019:2019.

23. Wellings $\mathrm{K}$, Jones KG, Mercer CH, Tanton C, Clifton S, Datta J, et al. The prevalence of unplanned pregnancy and associated factors in Britain : fi ndings from the third National Survey of Sexual Attitudes and Lifestyles ( Natsal-3 ); 2013. p. 6736.

24. Getachew FD. Level of Unintended Pregnancy and its Associated Factors among Currently Pregnant Women in Duguna Fango. 2015;2(2):75-88.

25. Ameyaw EK. Prevalence and correlates of unintended pregnancy in Ghana : analysis of 2014 Ghana Demographic and Health Survey; 2018. p. 1-6.

26. Kassahun EA, Zeleke LB, Dessie AA, Gersa BG, Derseh HA, Arage MW, et al. Factors associated with unintended pregnancy among women attending antenatal care in Maichew town, northern Ethiopia, 2017. BMC Res Notes. 2019:1-6. Available from. https://doi.org/10.1186/s13104-019-4419-5.

27. Mulatu T, Cherie A, Negesa L. Prevalence of Unwanted Pregnancy and Associated Factors among Women in Reproductive Age Groups at Selected Health Facilities in Addis. J Womens Health Care. 2017;6(5).

28. Izugbara C. Household characteristics and unintended pregnancy among women in Nigeria. Soc Med. 2011;26:8.

29. Tebekaw $Y$, Aemro B, Teller C. Prevalence and determinants of unintended childbirth in Ethiopia; 2014. p. 1-9. 
30. Connolly MP, Bahamondes L, Cecatti JG, Hu HX. The burden of unintended pregnancies in Brazil : a social and public health system cost analysis; 2014. p. 663-70.

31. CSA [Ethiopia] and ICF. Ethiopia Demographic and Health Survey; 2016. p. 2016

32. Ahmed KY, Page A, Arora A, Ogbo FA. Trends and determinants of early initiation of breastfeeding and exclusive breastfeeding in Ethiopia from 2000 to 2016. Int Breastfeed J. 2019;14(1):1-14.

33. Kassa N, Berhane Y, Worku A. Predictors of unintended pregnancy in Kersa; 2012. p. 1-7.

34. Doherty K, Arena K, Wynn A, Offorjebe OA, Sickboy O, Ramogola-masire D, et al. Unintended pregnancy in Gaborone, Botswana : A Cross-Sectional Study. Afr J Reprod Health. 2018;22:76-82.

35. Gizaw W, Fetene G, Mohammed S, Alemu A. Magnitude of Unplanned Pregnancy and its Associated Factors among Pregnant Women Attending Antenatal Care at Tepi General Hospital Sheka; 2018. p. 1-8,

36. Adeniyi OV, Ajayi Al, Moyaki MG, Ter Goon D, Avramovic G, Lambert J. High rate of unplanned pregnancy in the context of integrated family planning and HIV care services in South Africa; 2018. p. 4-11.

37. Martin E. Prevalence and Determinants of Unintended Pregnancies in Malawi. 2014;28(1):551-63.

38. Exavery A, Kanté AM, Njozi M, Tani K, Doctor HV, Hingora A, et al. Predictors of mistimed, and unwanted pregnancies among women of childbearing age in Rufiji , Kilombero, and Ulanga districts of Tanzania; 2014. p. 1-9.

39. Tadesse G, Yakob B. Risky sexual behaviors among female youth in Tiss Abay, a semi-urban area of the Amhara Region, Ethiopia. PLoS One. 2015; 10(3).

40. Taylor-Seehafer M, Rew L. Sexual behavior among adolescent women. JSPN. 2000:5(1):15-25.

\section{Publisher's Note}

Springer Nature remains neutral with regard to jurisdictional claims in published maps and institutional affiliations.

Ready to submit your research? Choose BMC and benefit from:

- fast, convenient online submission

- thorough peer review by experienced researchers in your field

- rapid publication on acceptance

- support for research data, including large and complex data types

- gold Open Access which fosters wider collaboration and increased citations

- maximum visibility for your research: over $100 \mathrm{M}$ website views per year

At BMC, research is always in progress.

Learn more biomedcentral.com/submissions 